\title{
Investigation of surface area of lakes and marshes from satellite images by using remote sensing and geographic information system integration in Iraq
}

\author{
Alaa Dawood, ${ }^{1, *}$, Yousif Kalaf $^{1}$, Nagham Abdulateef ${ }^{1}$, and Mohammed Falih $^{1}$ \\ ${ }^{1}$ College of Engineering, Baghdad University, Baghdad, Iraq.
}

\begin{abstract}
Water level and distribution is very essential in almost all life aspects. Natural and artificial lakes represent a large percentage of these water bodies in Iraq. In this research the changes in water levels are observed by calculating the areas of five different lakes in five different regions and two different marshes in two different regions of the country, in a period of 12 years (2001 - 2012), archived remotely sensed images were used to determine surface areas around lakes and marshes in Iraq for the chosen years. Level of the lakes corresponding to satellite determined surface areas were retrieved from remotely sensed data. These data were collected to give explanations on lake level and surface area fluctuations. It is important to determine these areas at different water levels to know areas which are being flooded in addition to the total area inundated .The behavior of hydrological regime of these lakes during the period was assessed using an integration of remote sensing and GIS techniques which found that the total surface area of the lakes had diminished and their water volumes reduced. The study further revealed that the levels of the lakes surfaces had lowered through these years.
\end{abstract}

\section{Introduction}

Lakes and marshes are water-filled areas of variable size, in a basin surrounded by land, apart from any river or other outlet that feeds or drains the lake. Lakes are located on land and not part of the ocean, and are therefore distinct from lakes, which are also larger and deeper than ponds. Docks and swamps can be contrasted with rivers or streams, which usually flow. However, most lakes are fed and drained by rivers. Natural lakes are generally found in mountain areas, fault zones and areas where there is persistent ice. [1][2] The late developments in this field and in satellite image processing have been very helpful in getting a lower coast and a more accurate data. Some of these applications are capable of estimating the percentage of moisture in the soil, the classifications of ground cover, and determining the land use and soil types. It is also possible by the use of satellite images to locate the most threatened areas by floods, this enables us to take the needed measurements to avoid such disasters by giving us the privilege of locating the needed dams to build according to specific standards. Also these remote sensing applications could be very useful in observing rivers flow. [2]

This enables us suggest the appropriate locations and designs for the future water controlling projects to be able to store the excessive flood water and use it back again in dry seasons. For a long time the water issue has been considered as one of the most important components to keep the environmental system in balance to provide all the human needs, especially in dry and semi dry climate countries, such as Iraq, where water is considered one of the most important natural resources, because it plays a great part in controlling population distribution and their economic activities especially in agriculture, so it has an important part in providing the needed food supply for the people. Also many people consider water supplies and their resources in the country as a matter of national security that may maintains the security of the country when water is available.

These reasons and several more show the real importance of water in keeping and maintain the water amount and distribution according to the needs. There for many elaborated and detailed studies should take place for further knowledge to the environmental and natural changes that have occurred and affected water lands during the past decades.[7] Now days in Iraq has developed a good number of water controlling projects, that can be used to regulate the water distribution for several uses so constant and detailed studies on water areas are required. In our research we have studied five different lakes in five different places through Iraq, we have calculated the areas of these lakes through and we have studied two different marshes in two different places through Iraq. In this study the areas of lakes and marshes were calculated by using integration of Geographic Information Systems (GIS). [5]

*Corresponding author: almurshedi.alaa@gmail.com 
GIS has grown into a powerful tool that can calculate and integrates driven types of spatial data and perform a variety of spatial analysis. This evolution has been driven by significant advances with the developed computer technology. GISs and environmental models function with a board spectrum of geospatial data that are used for diver's applications and spatial analyses at different scales .data are collected through observation, measurement, and inference. The examination and organization of data into a useful form produces information which then enables appropriate analysis and modelling [5]. The main objective of this paper is to estimate the rate and the extent of water loss from Iraqi lakes during the period 2001-2012. In addition, changes in the aerial extent and the volume of water within these lakes and marshes are further discussed and their potential environmental impacts are assessed.

\section{Water resources in Iraq}

Water bodies are very essential, they are the main working artery in life to keep the environmental system in balance especially in dry and semi dry climates. Especially during the second half of the past century due to four main reasons:

1. The largely decreased amount of falling water in the last decades in our planet affecting our country too, which led to cause scarcity of water in a lot of areas in Iraq. [8]

2. Large areas of Marshes, which represent half of the water surfaces in Iraq and occupy an area of $8900 \mathrm{~km}^{2}$, were dried for war purposes during the 1990 of the past century, the drying process of these marshland considered as an environmental and a social disaster. The southern regions of Iraq are still suffering from the devastating effects of this process. Although a lot of efforts were paid to refresh these marshes by filling them with water. [8]

3. The Iraqi politics and the bad planning regarding plans and future projects to provide the needed amount of water for the country, water projects in Iraq started in 1913 with Al-hindya dam, and then a few more dams were built in 1930 . The main purposes of these projects were, to maintain the water level in Iraqi rivers, prevent seasonal floods, irrigation and generating electricity. The development of life and the growing water needs created new goals for these water projects that were also used for water storage .That required the building of larger water reservoirs that could be used for storing water and then use it back again when needed. [8]

4. Many lakes and rivers were affected by the dams and irrigation projects that were built at the headwaters in neighboring countries such as Turkey, Iran and Syria. [8] Figure (1) shows the expected world map and the water distribution in year 2015 according to a special studies made by the UN. As it shown figure (1), most of the Arabic countries are facing large threats according to their water supplies, most of the Arabic countries, Pakistan and Iran are lying in the very high stress area. The total area of
Iraq is $437,072 \mathrm{~km}^{2}$, the land area is $432,162 \mathrm{~km}^{2}$ while the water area is $4,910 \mathrm{~km}^{2}$. The continuous decreasing of water resources in Iraq has considered one of the major problems that affecting the environmental system in Iraq.

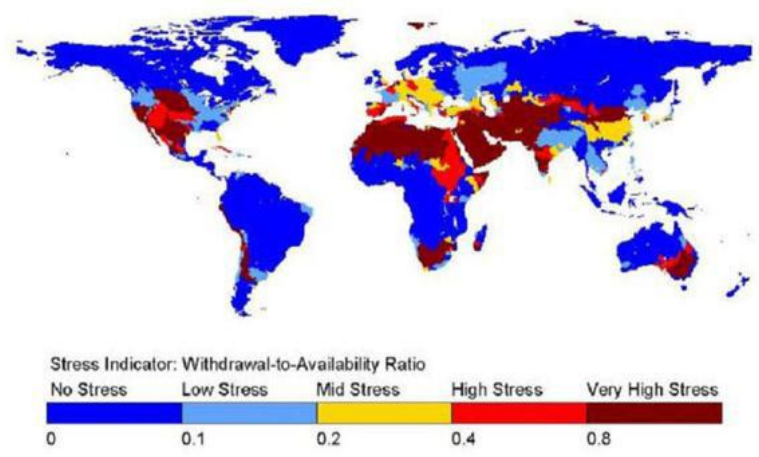

Fig. 1. Expected world map and water distribution in 2015

\section{Methodology and results}

The remote sensing data that were used in this research are Images from Landsat satellite (7, TM, ETM+, and MSS) and (ArcGIS9.3). Digitizing creates a polygon that represents the water body on the satellite image by outlining each water body in a digital image using a mouse cursor. This new polygon can then be used to estimate surface water area and can be compared to all previous and subsequent images The disadvantage to this is the time required to trace all of the pond shorelines in each region for each time frame. The advantage is an accurate representation of the water bodies in an image. [10]

The purpose of the paper is to study the fluctuations of the surface areas of lakes and marshes in Iraq. In order to delineate the boundaries of the lakes and marshes, satellite images was used, Land sat archive images, for the period (2001-2012) for lakes and the period (20052012) for marshes, were used as historical records for the situation of each lake and marsh during this periods .So we started by choosing five of the most important lakes of Iraq, (Al-Tharthar , AlHabanyah ,Derbendekhan, Dukan and Hemrin ), and choosing two of the most important marshes of Iraq, (Al-Hammar, Al-Hawayzah) these lakes and marshes were chosen due to their important role in regulating the water resources in Iraq and for their distributed locations in the center, northern and southern of Iraq to create a sample indicating how the water bodies have changed across different places of Iraq . After locating these seven water bodies we started collecting satellite images for every one of the mover the past 12 years since 2001 to 2012 for lakes and the past 8 years since 2005-2012. We have collected a single satellite image for each year for area measuring. 
Those images were all taken at the same time of the year to maintain the accuracy of the comparison and the research. We achieved this research by the use of the GIS technology as a remote sensing instrument, which enabled us to work on large scale areas, and provided the needed accuracy for the work. We used the collected satellite images of the lakes and marshes from the past 12 years and 8 years respectively to draw virtual lines to determine the borders of the lake and marshes in each year. These drawn borders enabled us to calculate the areas of the lakes and marshes for each time period a year and compare these areas with the areas calculated from other satellite images at earlier times. After calculating the areas for each lake we drew a diagram for every lake showing the changes in areas according to their years. In these diagrams the horizontal lines represented the year of the measured area while the vertical lines represented the areas in square kilometers. Figure (2), shows the studied lakes' distribution in Iraq.

\section{Data integration of GIS}

The GIS allows linking or merging of information that is difficult to connect by any other means. Thus, GIS can use sets of variables assigned to construct and analyze new variables. For example, using GIS technology, it is possible to combine agricultural records with hydrographic data to determine which streams will bear certain levels of fertilizer runoff. [3], [4] Agricultural records can indicate the amount of pesticides applied to a plot of land. [11] By identifying these parcels and intersecting them with streams, GIS can be used to predict the amount of runoff nutrients in each stream. Then with convergence streams, total downstream loads can be calculated as the stream enters the lake. [7]

Including artificial and natural lakes and marshes, these artificial lakes and marshes were made to store water of rivers in flood seasons and then to be used later when the water level in rivers is low. So these artificial and natural water reservoirs are very essential for water level to be controlled Figure (2), shows the studied lakes distribution in Iraq.

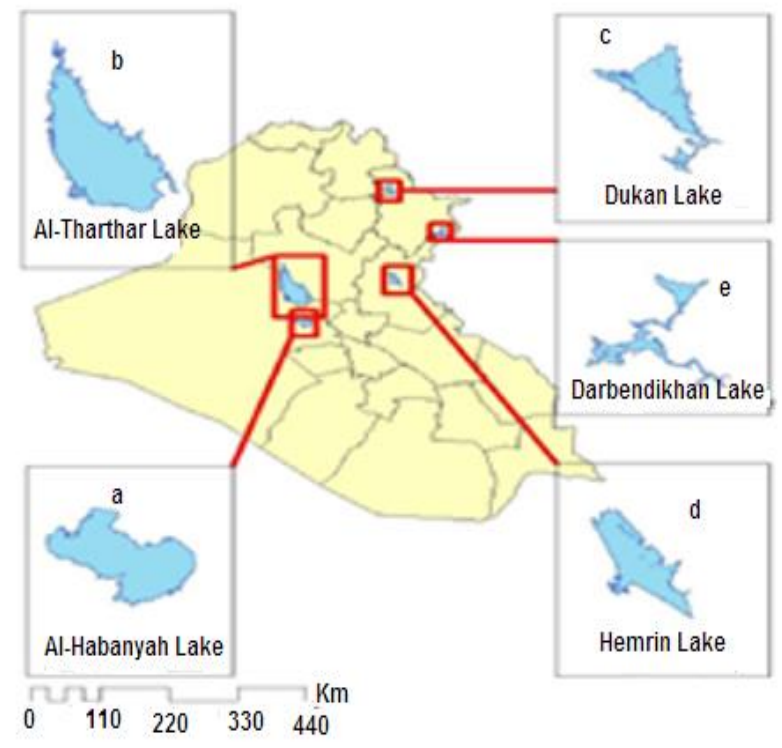

Fig. 2. The studied lakes distribution in Iraq.

\section{The Lakes}

\subsection{Al-Habanyah Lake}

It is a shallow natural lake and lies in a depression to the south of the Ramadi city. It faced a lot of changes in those 12 years, in 2001 the total area of the lake was (242.17) $\mathrm{km}^{2}$. When in the upcoming years the lake witnessed a rate of increasing in its area to become in 2012 (292.16) $\mathrm{km}^{2}$. Figure (2a), shows location of AlHabanyah Lake in Iraq and figures (3), (4) shows satellite images of lake across these 12 years and the area of the lake in each year.

\subsection{Al-Tharthar Lake}

Lake Tharthar, lies in the center of Iraq about 120 $\mathrm{km}$ northwest of Baghdad. Between the Tigris and the Euphrates rivers. It is the largest lake in Iraq. The construction of several dams has made it an important source for irrigation. Its size shrinks and expands dramatically with the seasons. The lake is deep and nutrient poor. Al-Tharthar Lake is the largest natural lake in Iraq, and one of the most important ones. The collected satellite images and calculations showed that since 2001 the lake area was increasing at each year until 2003 to achieve its largest average area. In 2001 the lake was $1922.183 \mathrm{~km}^{2}$ in area, and it began to increase at a rate of $21 \%$ per year from its original area in 2003, to have the area of $2357.526 \mathrm{~km}^{2}$. After 2003 the lake witnessed an obvious decreases in its area at a rate of 1.8 per year, to have a $1688.47 \mathrm{~km}^{2}$ of area in 2012 . Figure (2b), shows location of Al- Tharthar Lake in Iraq and figures (5), (6) shows satellite images of lake across these years and the area of the lake in each year. 


\subsection{Hemrin Lake}

Lake Hamrin, also known as the Diyala dam, is a man-made lake about $50 \mathrm{~km}$ northeast of Baquba, in the Diyala province of Iraq. It is a source of fish and also provides water to nearby palm groves and other farms, it was reported that due to the Iranian dam of the Lund River, the lake lost about $80 \%$ of its capacity [11]

The satellite images and areal calculations showed a lot of disparity in total area of the lake from one year to the next one, some of the years witnessed an obvious increasing in water level while in other ones the area decreased significantly. The Lake reached its highest level in 2003 when the surface area was $230.387 \mathrm{~km}^{2}$. While reaching its lowest in 2010 making only 80.421 $\mathrm{km}^{2}$ as a surface area. In 2012 the lake area was 130 $\mathrm{km}^{2}$. Figure (2d), shows location of Hamrin Lake in Iraq and figures (7), (8) shows satellite images of lake across these 12 years and the area of the lake in each year.

\subsection{Dukan Lake}

Dukan Lake is the largest lake in Iraqi Kurdistan. It is located near the city of Rania, and the reservoir on the small Zab created through the construction of Dukan dam multi-purpose dam to provide water storage, irrigation and hydropower. [9] The surface area of the lake is $270 \mathrm{~km}^{2}$. As such, the drainage basin of the Dukan Dam is 1700 $\mathrm{km}^{2}$. [6][8]

Dukan Lake also witnessed a less disparity than Hemrin Lake, and decreases in the surface area over the years. The spatial calculations showed that the lake has reached the maximum area of $361.585 \mathrm{~km}^{2}$ in 2002 , while reaching its minimum area with only $60.3 \mathrm{~km}^{2}$ in 2008. Figure (2c), shows location of Dukan Lake in Iraq and figures (9), (10) shows satellite images of lake across these 12 years and the area of the lake in each year.

\subsection{Darbendikhan Lake}

The satellite images for this lake showed that the surface area in 2001 was $50.1234 \mathrm{~km}^{2}$, over the following years the lake levels witnessed a lot of ups and downs, and the lake has reached its highest levels in 2004 scoring $95.45 \mathrm{~km}^{2}$. The rate of increasing in 2001 was $82 \%$ from its previous area in 2004 to have $95.45 \mathrm{~km}^{2}$ as a surface area, while in 2012 the lake has reached its lowest levels having only $41.546 \mathrm{~km}^{2}$. Figure (2e), shows location of Darbendikhan Lake location in Iraq and figures (11), (12) shows satellite images of lake across these 12 years and the area of the lake in each year.

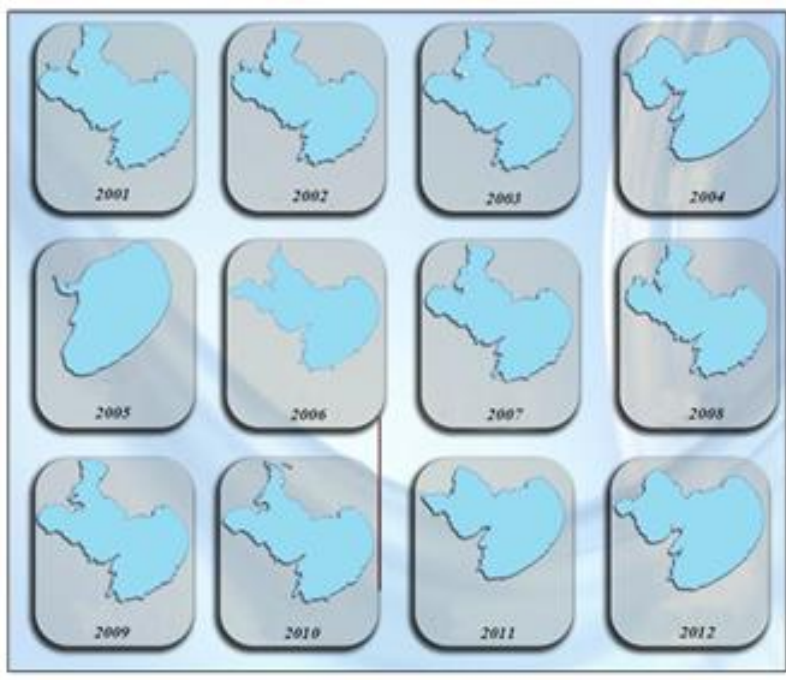

Fig. 3. Satellite images of Al- Habanyah Lake.

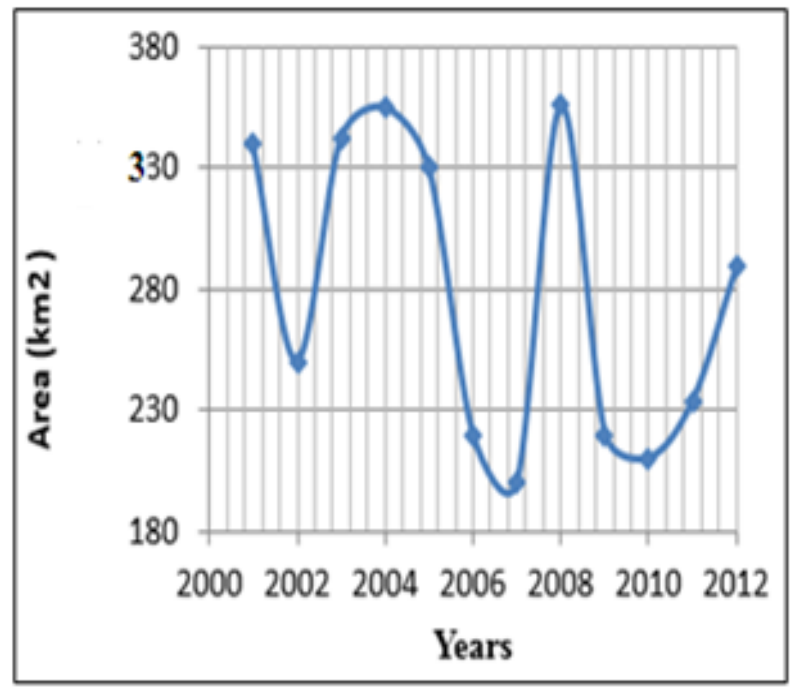

Fig. 4. The area of Al- Habanyah Lake.

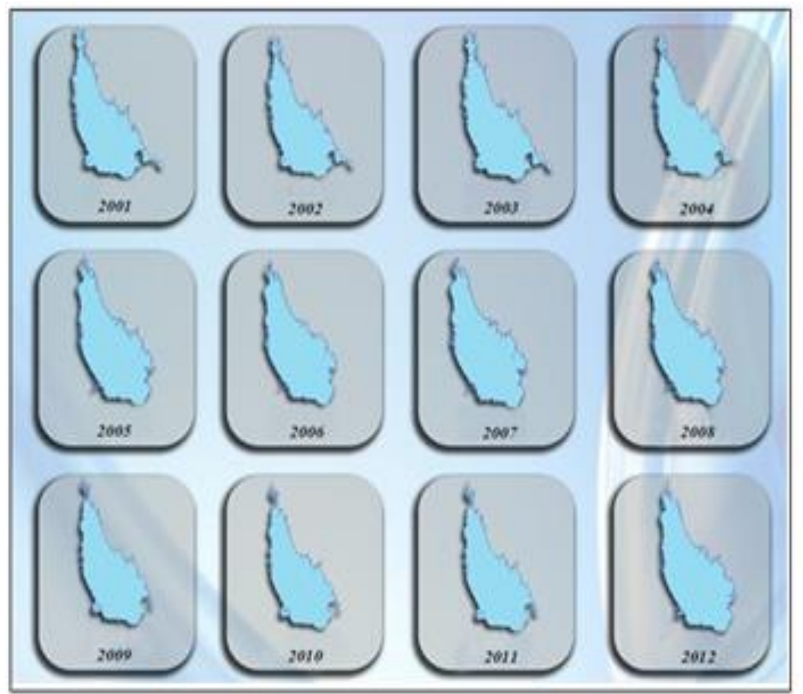

Fig. 5. Satellite images of Al- Tharthar Lake. 


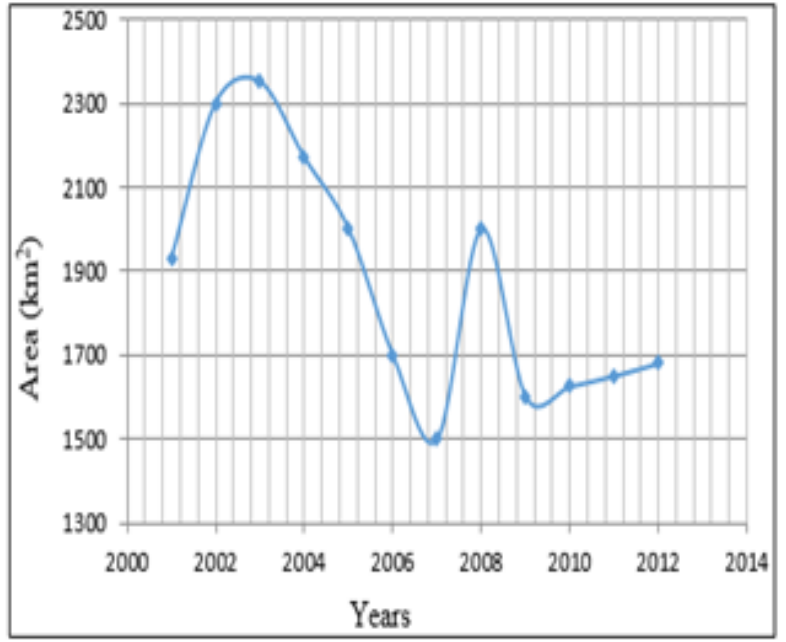

Fig. 6. The area of Al- Tharthar Lake

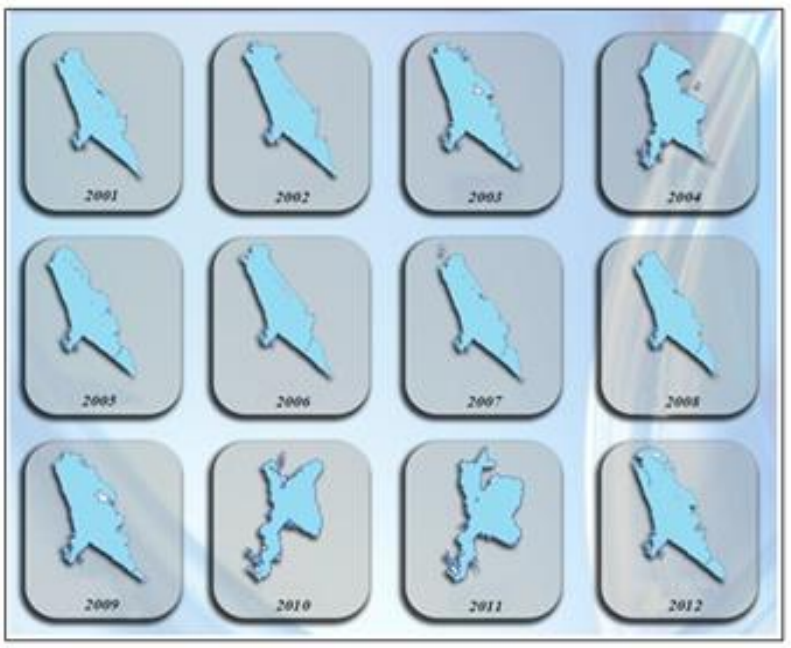

Fig. 7. Satellite images of Hemrin Lake.

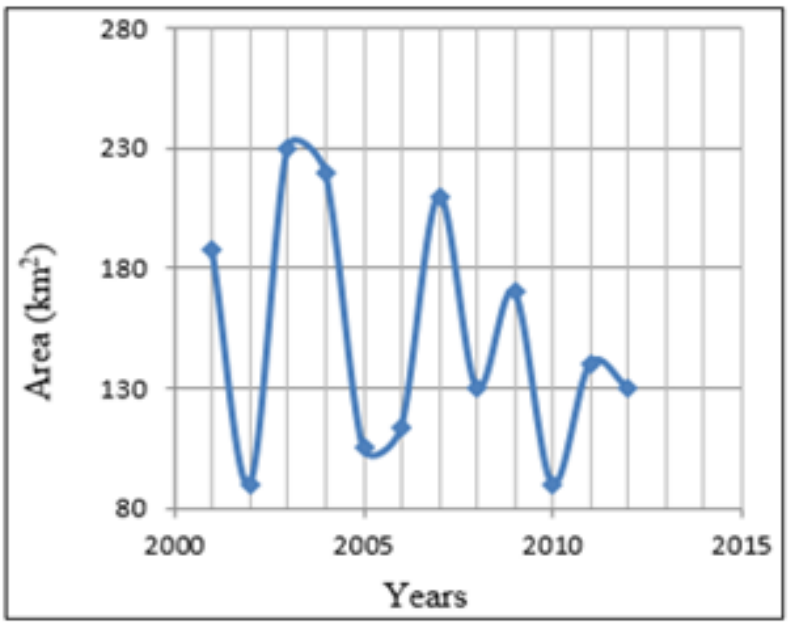

Fig. 8. The area of Hemrin Lake.

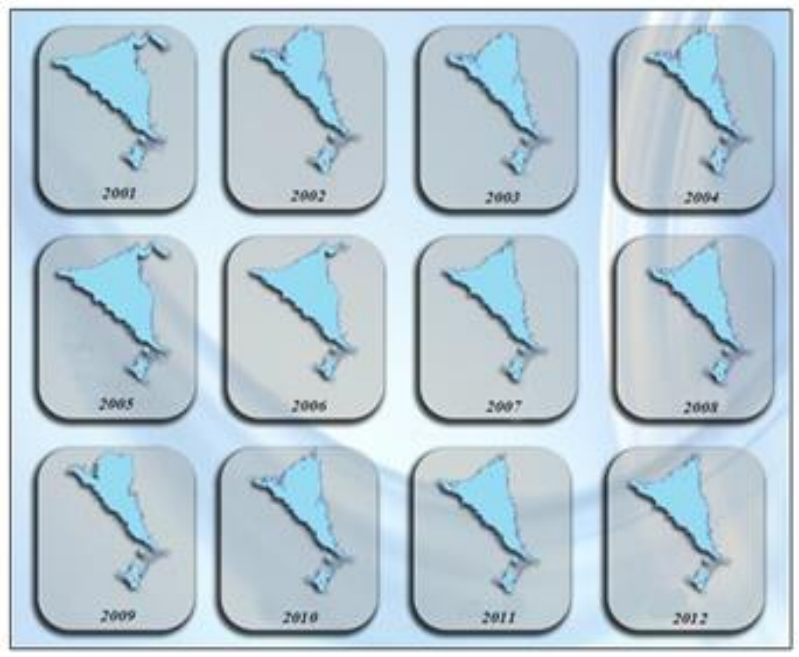

Fig. 9. Satellite images of Dukan Lake.

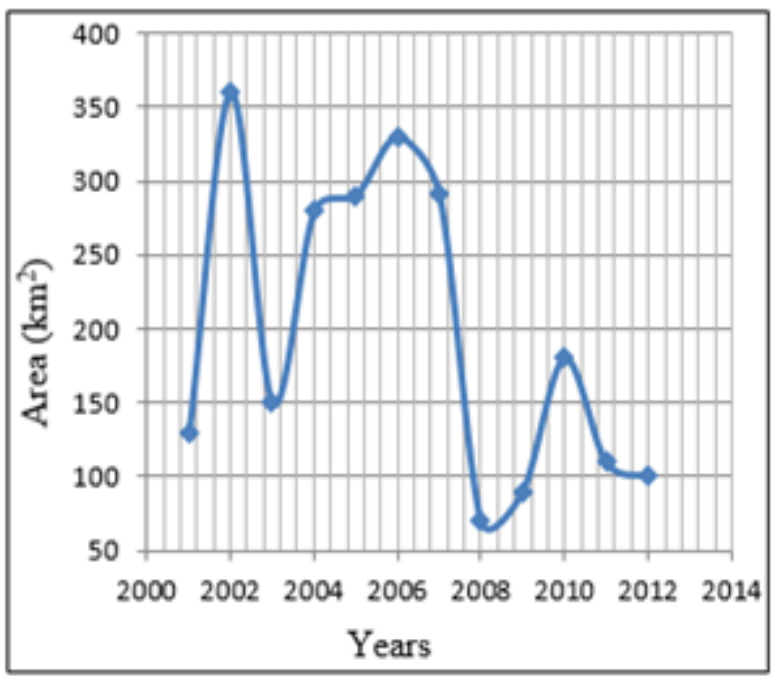

Fig. 10. The area of Dukan Lake.

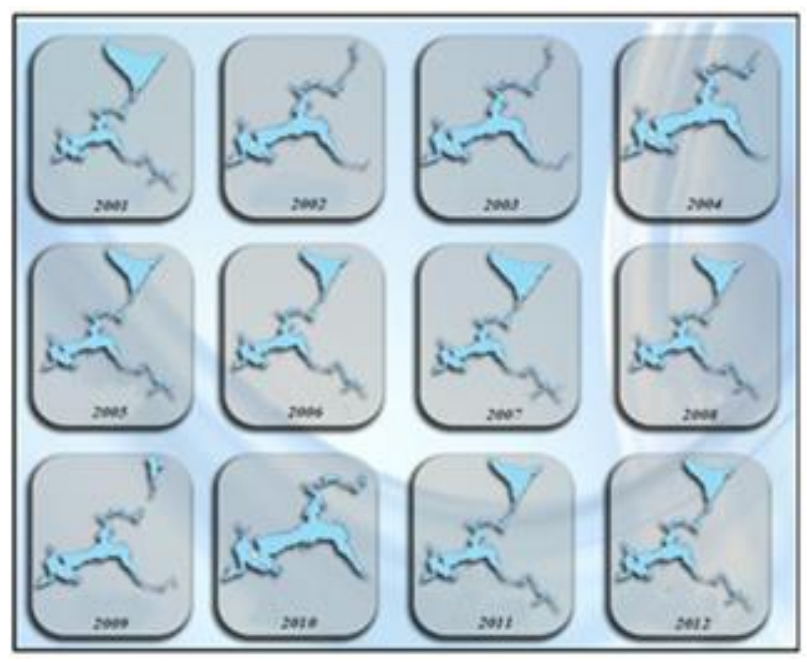

Fig. 11. Satellite images of Darbendikhan Lake. 


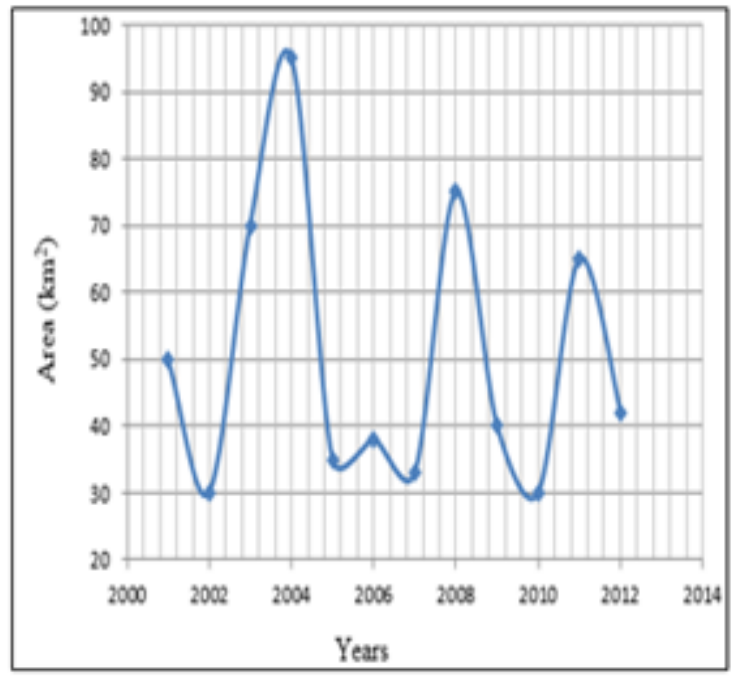

Fig. 12. The area of Darbendikhan Lake.

\section{Marshes}

\subsection{Al-Hammar marsh}

This marsh is located south of the Euphrates River in Iraq, and extends from Nasiriya in the west to the outskirts of Basrah at the Shatt al-Arab west. A length of $90 \mathrm{~km}$ and width of $25-30 \mathrm{~km}$. and the surface area of the maximum of about $2800 \mathrm{~km}^{2}$ in the flood season goes down to about $600 \mathrm{~km}^{2}$ during the dry season and is a permanent lake this lagoon with a vast area was dried by $94 \%$ during the past fifteen years the last was during this period. The spatial calculations showed that the marsh has reached the maximum area of $1092.87 \mathrm{~km}^{2}$ in 2011, while reaching its minimum area with only 611.87 $\mathrm{km}^{2}$ in 2005. Figures (13), (14) shows satellite images of marsh through these 8 years and the area of the marsh in each year.

\subsection{Al-Hawizeh marsh}

The swamps are located in the east of the Tigris and lie in Iran. The Iranian side of the marshes, known as the Great Hor, feeds on the Karkh River, while the Tigris, Mashra and Khela disperse the Iraqi side, with much less water than Karkh. During spring, the Tigris River may flow directly into the swamps.. Al-Hawizeh is one of the marshes of Iraq located in the provinces of Maysan and Basrah. It is bordered by the east of Iran. The Karkh River from Iran is located on the river. $80 \mathrm{~km}$ and width $30 \mathrm{~km}$. During the spring flow, the Tigris can flow directly into the marshes. The maximum area of the marshes reaches about $3000 \mathrm{~km}^{2} .21 \%$ and northern and central parts of the marshes are permanent but the Southern parts become seasonal in normal state. [8]

The satellite images for this marsh showed that the surface area in 2005 was $1600 \mathrm{~km}^{2}$, over the following years the marsh levels witnessed a lot of ups and downs, and the lake has reached its highest levels in 2006 scoring $1671.45 \mathrm{~km}^{2}$. The rate of decreasing to 2001 was $45 \%$ from its previous area in 2010 to have 1010 $\mathrm{km}^{2}$ as a surface area, while in 2011 and 2012 the lake has increased levels having only 1100.54 and 1190.67 $\mathrm{km}^{2}$ respectively. Figures (15), (16) shows satellite images of marsh through these 8 years and the area of the marsh in each year.

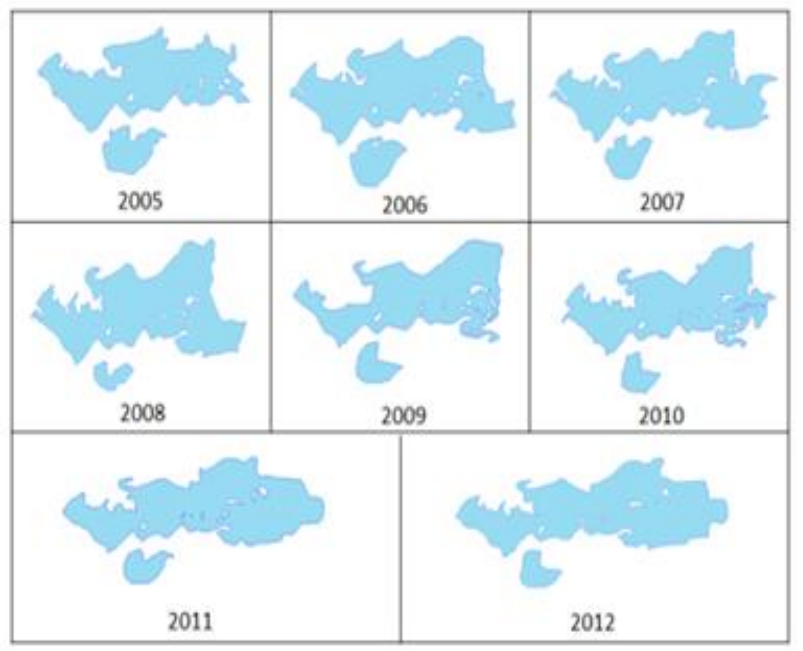

Fig. 13. Satellite images of Al-Hammar marsh.

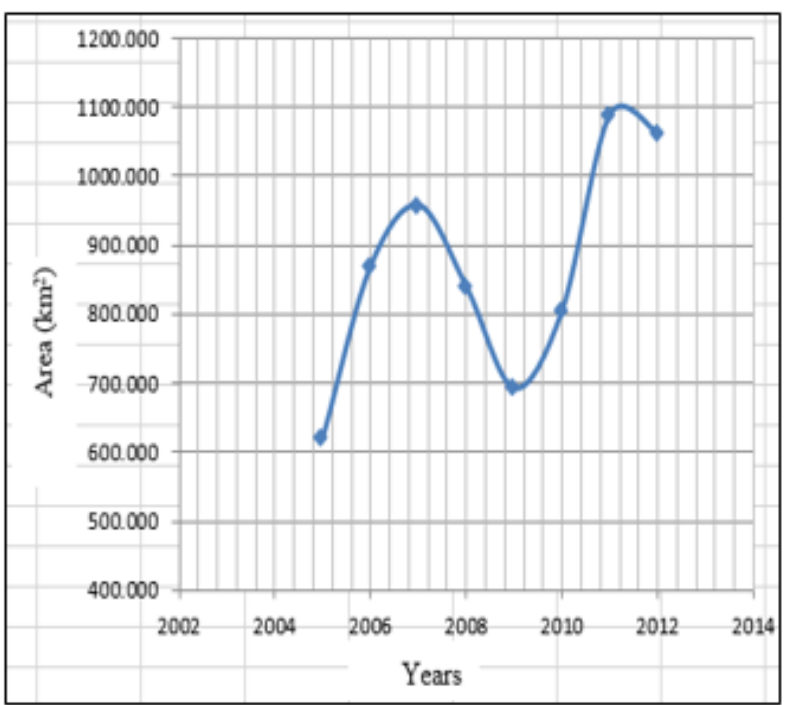

Fig. 14. The area of Al-Hammar marsh.

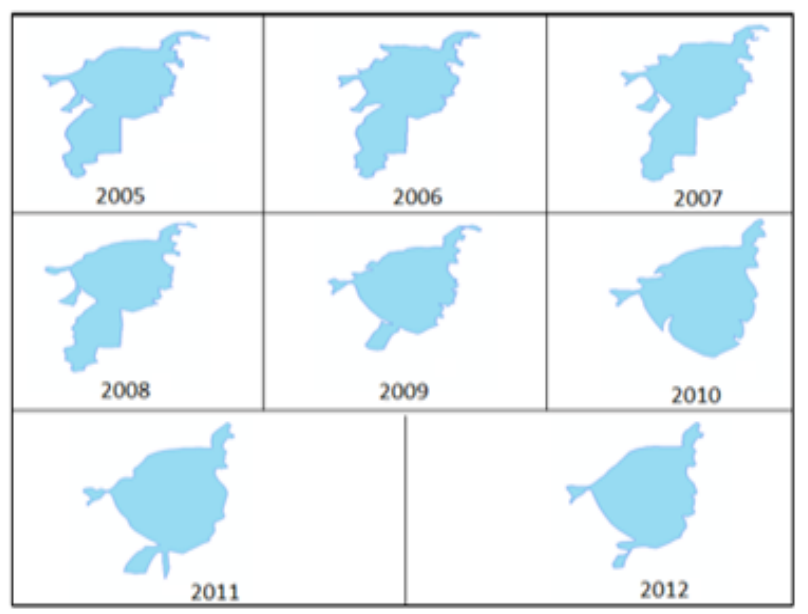

Fig. 15. Satellite images of Al-Hawizeh marsh. 


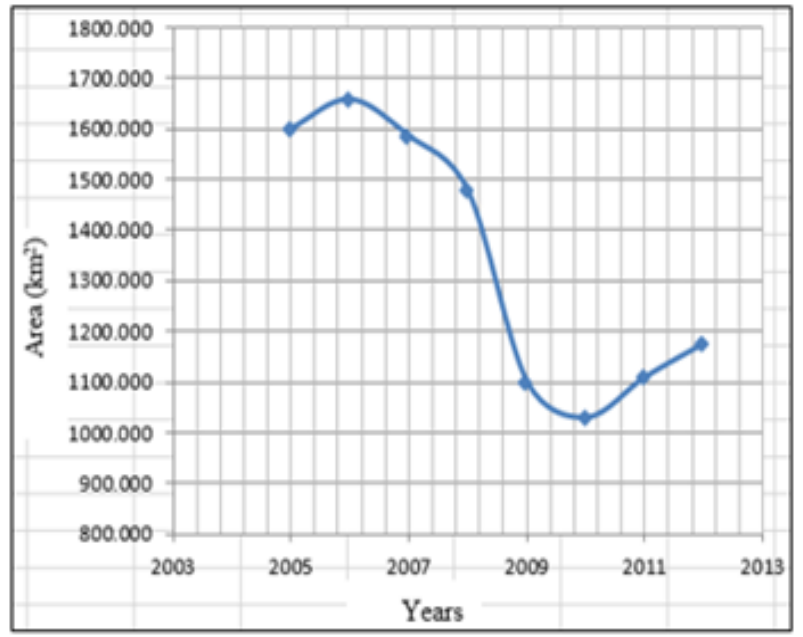

Fig. 16. The area of Al-Hawizeh marsh.

\section{Conclusions}

Remote sensing and demographic analysis in order to assess recent surface hydrological and environmental changes in lakes and marshes in Iraq, and concluded that:

1. Due to its location in a highly arid zone, Iraqi lakes are exposed to high evaporation rates and result in an annual loss of about $2.5 \mathrm{~m}$ from their water column. Only $10 \%$ of this amount is recharged to the aquifers under the lakes.

2. In this research we recommend that we take the measures necessary to make the most of the huge amount of water resources before you lose completely through evaporation.

3. Lakes and marshes in Iraq are the main surface water resources, and given the importance of these lakes and marshes, we conducted a study to determine the changes that have occurred to the areas of these lakes during the past 12 years for lakes and the past 8 years for marshes. These changes are usually influenced by political, economic and climatic conditions.

4. GIS techniques were applied to achieve this study and were calculated for each polygon and compared to the corresponding lakes and marshes of the images at later times. The results indicate that the total area of these five lakes in 2012 decreased by $15.567 \%$ of the total area in 2001. And the results indicate that the total area of $\mathrm{Al}$ hammar marsh 2012 increased by $85 \%$ of the total area in 2005 , but the results indicate that the total area of Al Hawizeh marsh 2012 decreased by 34\% of the total area in 2005.

5. During these 12 years of our research (2001 to 2012), there was a marked disparity in the lake areas, and in some years the regions were in an increase while in other regions. In general, 2008 recorded the minimum surface area of these lakes in an area of only $1795.1567 \mathrm{~km}^{2}$ while the highest level was in 2003 when the total area was $3455.506 \mathrm{~km}^{2}$.

6. During these 12 years of our research (2001 to 2012), there was a marked disparity in the marshes areas, and in some years the regions were in an increase while in other regions. In general, 2011 recorded the maximum surface area of these marshes in an area of only $2200.1435 \mathrm{~km} 2$ while the lowest level was in 2009 when the total area was 1810.436 $\mathrm{km}^{2}$

\section{References}

1. R.G. Bryant, M.P. Rainey , JORSE 12, 360 (2002)

2. C. Castaneda, J. Herrero, M.A. Castared JAE 63, 497 (2005)

3. Chang K.T. Introduction to Geographic Information System (3d .Ed. McGraw Hill international Edition, 2006)

4. Demers M. Geographic Information System Modeling in Raster (New York, Wiley, 2002)

5. ESRI, Arc GIS 9.3 Help Manual, Environmental System Research Institute Inc. (Redlands, Californie 2008)

6. A.K. Fink, I.D. Ostrizhnov, PTE 17,10 (1984),

7. R.H. French, J.J. Miller, C. Dettling, J.R. Carr, JH 81, 67 (2006)

8. Albertine J. Dukan Dam, (Encyclopédie of the modern Middle East. New York, 1996)

9. Konecny G. Geo information Remote sensing, Photogrammetric and Geographic Information System, (Taylor \& Francis, London and New York 2003) ngley P.A. Goodchild M.F. Maguire D.J. Rhind D.W., Geographical Information Systems and Science, (England, John Wiley \& Sons Ltd, USA, 2005)

10. Roaf M. The Hamrin Sites, (BSA, London 1992) 